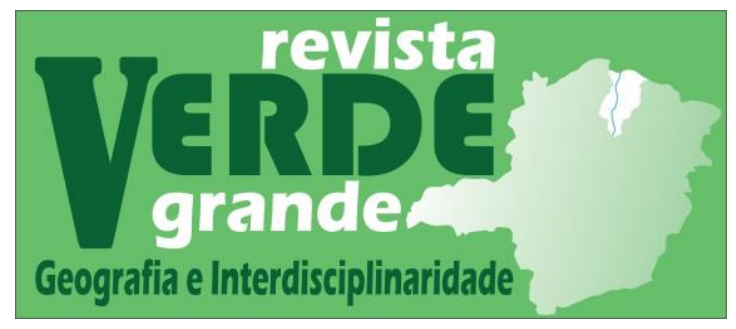

\title{
O TRABALHO DE CAMPO COMO METODOLOGIA DE ENSINO DE GEOGRAFIA: APLICABILIDADE NO MUNICIPIO DE SETE LAGOAS-MG
}

\author{
Field work as a geography teaching methodology: applicability in the municipality of \\ Sete Lagoas-MG
}

Ricardo Henrique Palhares ${ }^{1}$ https://orcid.org/0000-0002-9786-3683

Alysson Cley de Souza Ferreira ${ }^{2}$ https://orcid.org/0000-0002-9439-9280

$1 \quad$ Professor do Departamento de Geociências e PPGEO - UNIMONTES. E-mail:
ricardo.palhares@ unimontes.br
${ }^{2}$ Mestrando em Geografia - PPGEO - UNIMONTES. E-mail: alyssongeo@ hotmail.com

\section{Resumo}

De modo geral, a criação de um município, em qualquer de suas fases (povoado, vila ou cidade) esteve relacionado a três fatores: importância (local ou regional), condições do local (geologia, geomorfologia, recursos naturais) e potencial de desenvolvimento atual e futuro (econômico, humano e político). Sete Lagoas foi criada inicialmente com estes três aspectos em posição secundária devido à proximidade e relação com a Região Metropolitana de Belo Horizonte. Levantar estes aspectos em campo auxilia no entendimento do arcabouço físico e social e favorece o entendimento de como e quando o desenvolvimento continuará a ocorrer no município e região. Diante da importância desta temática, o estudo pretende realizar uma série de análises a respeito de como se processa o trabalho de campo no ensino da Geografia Urbana, no que tange as observações efetuadas no município de Sete Lagoas e sua região. A adoção de estudos de Geografia Urbana com atividades de campo propicia aos professores de Geografia melhores condições de repassar aos alunos conhecimento teórico e técnico, assim como incentivo na criação de ideias e concepções para o futuro do local a ser estudado. Os resultados apresentados demonstram que a prática de campo é fundamental ao profissionais de geografia, visto que a teoria associada a prática auxilia no desenvolvimento de qualquer plano municipal, desde sua instalação, desenvolvimento e conclusão, mesmo que estes três estágios estejam sempre sendo modificados ou atualizados.

Palavras-chave: Trabalho de campo, Ensino de Geografia, Metodologia de ensino, Sete Lagoas.

\footnotetext{
Abstract

In general, the creation of a municipality, in any phase (village or city) was related to three factors: importance (local or regional), local conditions (geology, geomorphology, natural resources) and potential for current and future development (economic, human and political). Sete Lagoas was created initially with these three aspects in a secondary position due to its proximity and relationship with the Metropolitan Region of Belo Horizonte. Raising these aspects in the fieldwork helps to understand the physical and social framework and favors the understanding of how and when development will continue to occur in the municipality and region. In view of the importance of this theme, the study intends to carry out a series of analyzes regarding how the fieldwork in the teaching of Urban Geography is processed, regarding the observations made in the municipality of
} 
O trabalho de campo como metodologia de Ensino de Geografia: aplicabilidade no municipio de Sete Lagoas-MG

Ricardo Henrique Palhares; Alysson Cley de Souza Ferreira

Sete Lagoas and its region. The adoption of Urban Geography studies with field activities provides Geography teachers better conditions to pass on theoretical and technical knowledge to students, as well as incentive to create ideas and concepts for the future of the place to be studied. The results presented demonstrate that field practice is fundamental to geography professionals, since the theory associated with the practice assist in the development of any municipal plan, since its installation, development and conclusion, even though these three stages are always being modified or updated.

Keywords: Fieldwork, Geography teaching, Teaching methodology, Sete Lagoas.

\section{INTRODUÇÃO}

A Geografia é a ciência que estuda o espaço geográfico no que concerne à relação entre sociedade e natureza. Tanto o espaço produzido pelas sociedades rurais e urbanas quanto o espaço natural superficial são objetos de estudo dessa importante ciência, que opera os seus métodos e suas abordagens em categorias de análise, tais como a paisagem, o lugar, a região e o território. Nesse sentido, o trabalho de campo é de fundamental importância para a observação dos objetos analisados por essa ciência e instrumento didático importante no ensino de Geografia, uma ciência que se encarrega de explicar os fenômenos resultantes da relação sociedade/espaço (ALENTEJANO; ROCHA LEÃO, 2006).

Desde que seja previamente planejado e realizado com eficiência, o trabalho de campo pode transformar-se em um dos mais importantes métodos de estudo, não só para a Geografia enquanto campo científico, mas para a Geografia Escolar. Segundo Cavalcanti (1998), ambas analisam a realidade pela mesma perspectiva, porém, a Geografia Escolar, cada vez mais atual e dinâmica é um feixe de referências que busca a ligação do fenômeno estudado com a experiência cotidiana dos alunos, destacando elementos correlatos a sua vivência. Esta relação favorece um posicionamento crítico aos estudantes e uma formação mais completa a cerca da análise do processo ensino-aprendizagem.

Diante disso, o objetivo do presente estudo é realizar uma série de análises a respeito de como se processa o trabalho de campo no ensino da Geografia Urbana, no que tange aos conhecimentos prévios, experiências e observações efetuadas no município de Sete Lagoas e sua região. A atividade ocorreu no dia 10 (dez) de novembro de 2007, tendo como ponto de partida a cidade de Belo Horizonte e destino à cidade de Sete Lagoas. O percurso de ida foi realizado através da MG-424 que liga Belo Horizonte a Sete Lagoas e a volta pela BR-040 que liga o Rio de Janeiro a Brasília. 
O trabalho de campo como metodologia de Ensino de Geografia: aplicabilidade no municipio de Sete Lagoas-MG

Ricardo Henrique Palhares; Alysson Cley de Souza Ferreira

O trabalho de campo foi realizado com alunos da Pós-Graduação em Geografia Tratamento da Informação Espacial da PUC Minas, sendo supervisionada pelo professor Oswaldo Bueno Amorim Filho, responsável pelas explanações sobre a paisagem urbana, no seu contexto urbano e regional, e pelo professor Heinz Charles Kohler, responsável pelas explanações sobre a parte física (geologia e geomorfologia) da cidade e sua região.

As análises pormenorizadas ao longo desse estudo demonstram a eficácia desta metodologia no ensino da Geografia, bem como sua importância como instrumento de interação entre os atores envolvidos no processo ensino aprendizagem, na implementação da teoria e prática. As descrições e conhecimentos obtidos em campo mostram a eficiência da operacionalização da atividade pelos professores, servindo de referência e/ou sugestão para futuras propostas pedagógicas.

\section{CARACTERIZAÇÃO DA ÁREA DE ESTUDO}

Sete Lagoas possui uma extensão territorial de $536,644 \mathrm{~km}^{2}$ e está situada na região central do Estado de Minas Gerais, na Zona Metalúrgica, ficando a $74 \mathrm{~km}$ da capital Belo Horizonte, em direção ao norte. Configura-se, hoje, segundo Amorim Filho (2005), como exemplo de cidade de porte médio de nível superior com crescente aumento de população, e com grande nível de centralidade e ausência de outro centro competidor e/ou articulado. Segundo estimativas, a população atual é em torno de 239.639 habitantes (IBGE, 2019).

Mesmo estando próxima da terceira maior Região Metropolitana do Brasil, Sete Lagoas possui uma respeitável autonomia em relação à metrópole belo-horizontina, devido a uma economia dinâmica, sendo uma cidade de rápido crescimento. As principais vias de acesso (rodovias BR-040, MG-424 e MGR-238) são, hoje, fatores favoráveis à liderança regional do município, o que a duplicação do trecho da BR-040 (Rio-Brasília), que liga Sete Lagoas a Belo Horizonte, muito favoreceu (Figura 1).

Essa conexão também integrou as relações das funções urbanas praticadas por Belo Horizonte e Sete Lagoas em um novo contexto metropolitano. Sete Lagoas faz parte na atualidade de um cinturão do colar metropolitano de Belo Horizonte e sofre a influência da gravitação econômica e do poder central emanado pela metrópole (AMORIM FILHO, 2005).

O município possui limites com outros municípios: ao norte, limita-se com Araçaí, Caetanópolis, Jequitibá e Paraopeba; ao sul, com Esmeraldas e Capim Branco; a leste com 
O trabalho de campo como metodologia de Ensino de Geografia: aplicabilidade no municipio de Sete Lagoas-MG

Ricardo Henrique Palhares; Alysson Cley de Souza Ferreira

Funilândia e Prudente de Morais; a oeste com Inhaúma. A distância entre estes municípios varia entre 9 a $48 \mathrm{~km}$, sendo as estradas, em sua maioria asfaltadas.

Figura 1: Sete Lagoas no contexto de Minas Gerais

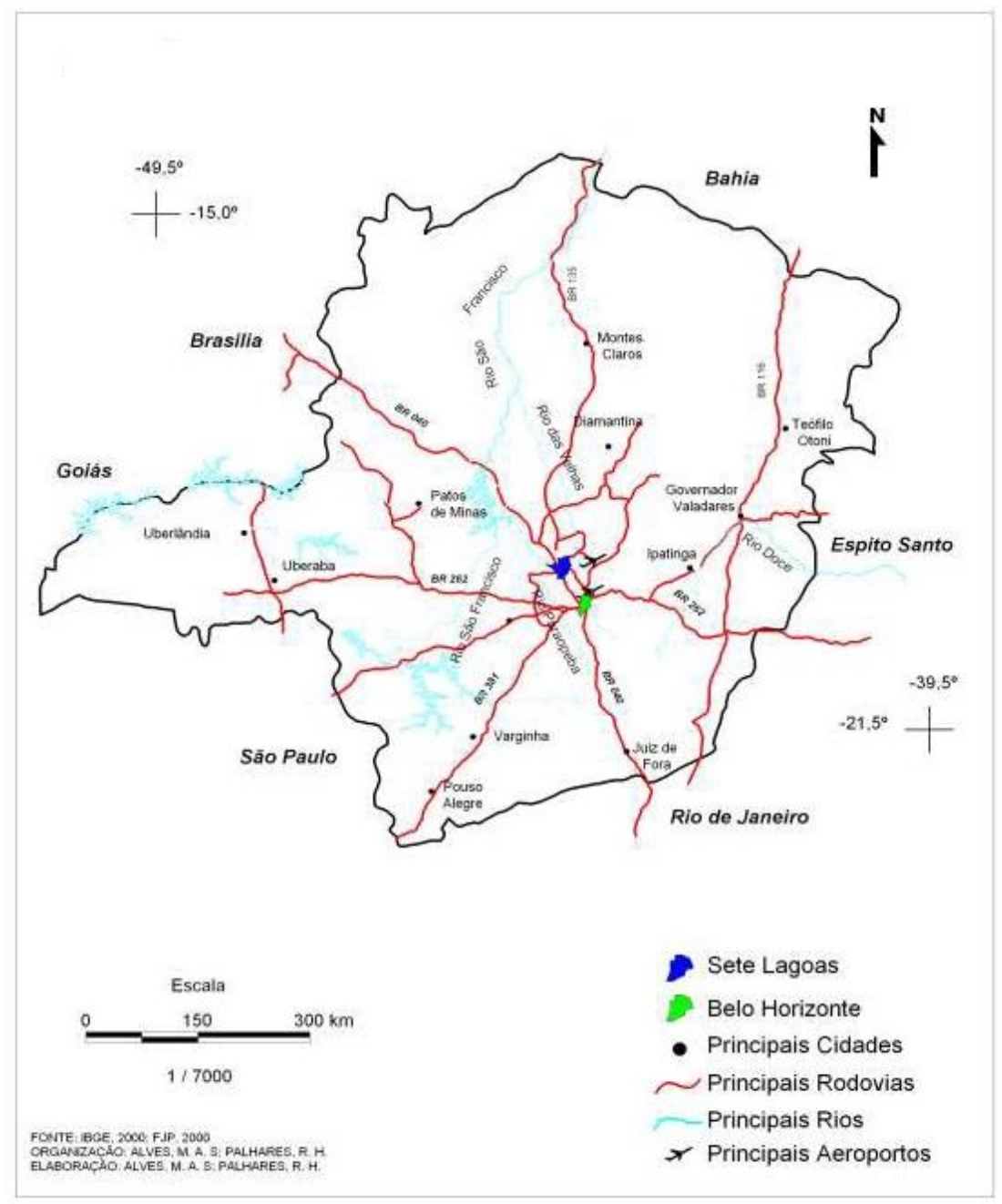

Fonte: Base digital IBGE, 2019.

O relevo do município de Sete Lagoas é formado de um imenso Planalto com algumas elevações. Situado dentro da chamada Depressão São Franciscana, o relevo do município de Sete Lagoas é do tipo ondulado, com altitudes que variam de 700 a 1.076 metros. A altitude média do município é de 766 metros. Destaca-se na região altitudes superiores a 1.000 metros na Serra de Santa Helena, localizada a noroeste da cidade. Esta serra constitui o principal divisor de água dos rios Paraopeba e das Velhas, duas bacias que drenam o município. 


\section{O trabalho de campo como metodologia de Ensino de Geografia: aplicabilidade no municipio de} Sete Lagoas-MG

Ricardo Henrique Palhares; Alysson Cley de Souza Ferreira

De acordo com o professor Kohler ${ }^{1}$, parte considerável do município está situada sobre rochas carbonáticas de idade Proterozóico Superior (Grupo Bambuí), as quais, são responsáveis pelas feições cársticas que caracterizam sua paisagem: dolinas, ressurgências, sumidouros, grutas, mogotes, entre outros. Todos esses fenômenos estão intimamente associados à presença e à ação da água em condições de subsuperfície, bem como à acentuada fragilidade ambiental dessas áreas, cuja esculturação da paisagem ocorre sobre unidades litológicas acentuadamente solúveis. A herança cárstica impressa no relevo legou ao município diversas lagoas associadas à dolinamentos que deram nome à cidade, dentre as quais, se destacam: Paulino, José Félix, Catarina, Boa Vista, Matadouro, Chácara e Cercadinho.

O clima dominante na região é o tropical de altitude, com temperatura média de $19^{\circ} \mathrm{C}$ a $22^{\circ} \mathrm{C}$. Seu regime de chuvas apresenta uma precipitação pluviométrica de 1.100 a $1.450 \mathrm{~mm}$, com estiagem no inverno. A vegetação natural predominante na região é o cerrado, com espécies vegetais como Jequitibá, Vinhático. Hoje, encontra-se bastante degradada ou foi substituída por pastagens e plantações.

Além da indústria dinâmica, a região possui uma atividade agrícola importante, fazendo parte do cinturão verde de Belo Horizonte, e com um setor turístico também bastante dinâmico. A cidade que era tradicionalmente ligada ao setor agropecuário tem passado, particularmente nas duas últimas décadas, por um processo de reconversão da economia, com a consolidação como polo industrial regional. E neste processo de industrialização do município, foram importantes ao longo da história e existência de alguns, como o Ciclo da Estrada de Ferro Central do Brasil, inaugurado em 1906, (posteriormente RFFSA), Ciclo do Cristal iniciou-se por volta de 1940, Ciclo da Pecuária Leiteira na década de 1950, Ciclo do Ferro Gusa nas décadas de 1970 e 1980 e por último o Ciclo das indústrias de autopeças/montadoras iniciado na década de 1980.

\section{PROCEDIMENTOS E TÉCNICAS DE CAMPO}

Relacionar os temas estudados em sala de aula com o que ocorre fora dela é algo que deve estar no radar de todos os professores. Entre as formas de realizar essa tarefa, uma das mais consagradas é o trabalho de campo. Ao analisar os procedimentos e técnicas da atividade em campo é importante levar em consideração que a organização da visita in loco é apenas uma das etapas.

\footnotetext{
${ }^{1}$ Relatos e explanações transcritos de gravações feitas no trabalho de campo (nov. de 2007).
} 


\section{O trabalho de campo como metodologia de Ensino de Geografia: aplicabilidade no municipio de}

Sete Lagoas-MG

Ricardo Henrique Palhares; Alysson Cley de Souza Ferreira

Previamente, o trabalho de campo em Sete Lagoas partiu de uma reflexão sobre os objetivos a serem alcançados com a referida atividade, ou seja, confirmar ou refutar o conteúdo assimilado nas aulas da disciplina de Geografia Urbana. Coube aos professores auxiliar os alunos para que não perdessem o foco, direcionando a atenção aos aspectos essenciais ao trabalho.

É importante salientar, que para qualquer trabalho de campo, seja acadêmico ou profissional, é recomendado se ter, antecipadamente, uma série de itens e providências, já prontas ou aptos para serem desenvolvidos durante o próprio campo. Abaixo, listamos em maneira geral, alguns dos procedimentos adotados:

$\checkmark$ Dados e informações sobre o local a ser visitado: distâncias totais a serem percorridas e forma de percurso (a pé, de carro, etc.), além das condições dos acessos existentes;

$\checkmark$ Informações sobre condições do tempo e do melhor horário do dia para se iniciar e terminar o campo (pluviosidade, temperatura local, etc.);

$\checkmark$ Material didático sobre o acesso, local de estudo e foco do estudo ou análises: cartas geográficas, topográficas, de aspectos fisiográficos (geomorfologia, geologia, vegetação, etc.), dependendo do foco do estudo a ser realizado;

$\checkmark$ Ferramentas, utensílios e bens de consumo antes, durante e após o campo: roupa e calçados adequados, alimento, água, repelente, protetor solar, capas de chuva, bússolas, GPS, martelos, sacos de amostra, máquina fotográfica, barracas, caderneta de campo, etc. Dependendo do foco e do local a ser estudado;

$\checkmark$ Determinação e comunicação prévia para parentes, professores, instituições sobre as rotas ou traçados do percurso até o local a ser analisado, ao longo deste local (trilhas, estradas, etc.), e seu retorno. Estimativa de tempo de ida, trabalho de campo e retorno;

$\checkmark$ Resumo do que se pretende levantar, estudar verificar em campo e ao longo de todos os percursos. Anotações em cadernetas de campo, cadernos ou equipamentos eletrônicos. Dependendo do local e foco do estudo a ser realizado;

$\checkmark$ Acampamento de profissional ou instrutor sobre e para os assuntos a serem levantados em campo;

$\checkmark$ Veículo adequado, revisado e com equipamentos de comunicação operantes para caso de necessidade de acionar apoio ou ajuda. 
O trabalho de campo como metodologia de Ensino de Geografia: aplicabilidade no municipio de Sete Lagoas-MG

Ricardo Henrique Palhares; Alysson Cley de Souza Ferreira

Com o checklist supracitado e providenciado previamente, pode-se dar início ao trabalho de campo. No caso em questão, estudo da Geografia Urbana do município de Sete Lagoas, alguns destes itens ou pontos não precisaram ser providenciados. Coube aos professores planejar o campo antecipadamente em sala de aula, utilizando-se cartas topográficas e geológicas, imagens de satélite, roteiros, fundamentação teórica sobre as paradas a serem realizadas, tempo de campo e foco. Em relação aos alunos, além das observações em campo, a utilização de materiais como caderneta de campo, GPS, bússola e máquina fotográfica foram imprescindíveis para o bom andamento da atividade.

\section{METODOLOGIA: Paradas e observações em campo}

Para a observação e análise da Geografia Urbana do município de Sete Lagoas, alguns aspectos principais foram listados. Ao se observar e analisar estes aspectos, os alunos puderam ter ao final, a ideia do todo do que se pretendia ensinar.

Para tanto, foram definidos locais ou pontos de parada, como melhor local ou posição para os aspectos levantados anteriormente. Exemplo: na primeira parada foi melhor visualizada e analisada a zona de transição regional entre Belo Horizonte e Sete Lagoas. Na segunda parada, foi melhor observado e analisado o sítio geográfico de Sete Lagoas, avanço e dinamismo urbano, e assim por diante.

O trabalho de campo foi feito adotando o sistema de paradas supracitados, totalizando ao final do campo um total de 5 (cinco) paradas, listadas e descritas abaixo:

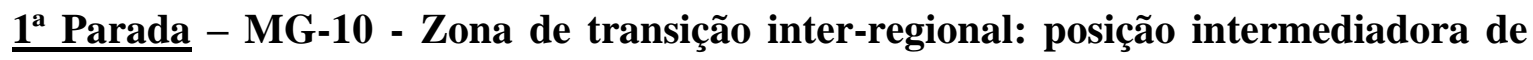

Belo Horizonte e Sete Lagoas. Coordenadas UTM: 609988 E, 7811662 S. 23K

Nesta parada foi dado ênfase no aspecto regional da cidade de Sete Lagoas. Partindo desta visão, os alunos puderam perceber a transição existente entre a Região Metropolitana de Belo Horizonte e a zona intermediadora até a sede de Sete Lagoas (Figura 2).

A espacialização contempla desde a geologia e geomorfologia, passando pelas vias de acesso, recursos naturais até a parte física da cidade em si. Exemplo: pela altitude deste ponto de observação, pôde-se observar as escavações naturais ao longo das bacias do Rio das Velhas e as planícies existentes margeando estas escavações (planícies intracratônicas).

Nesse ponto foi possível observar o quanto a geologia favoreceu o surgimento das vias e zonas de escoamento, acessos e rodovias. Além disso, observou-se o Aeroporto de 
O trabalho de campo como metodologia de Ensino de Geografia: aplicabilidade no municipio de Sete Lagoas-MG

Ricardo Henrique Palhares; Alysson Cley de Souza Ferreira

Confins, um dos maiores do país. Sua construção passou por problemas de fundação e distribuição espacial devido ao relevo carstico da região (abatimento de solos e blocos por dissolução) o que tornou os serviços e engenharia nas fundações e drenagens de suma importância para que o próprio aeroporto existisse.

Figura 2: Zona de transição: RMBH e Sete Lagoas

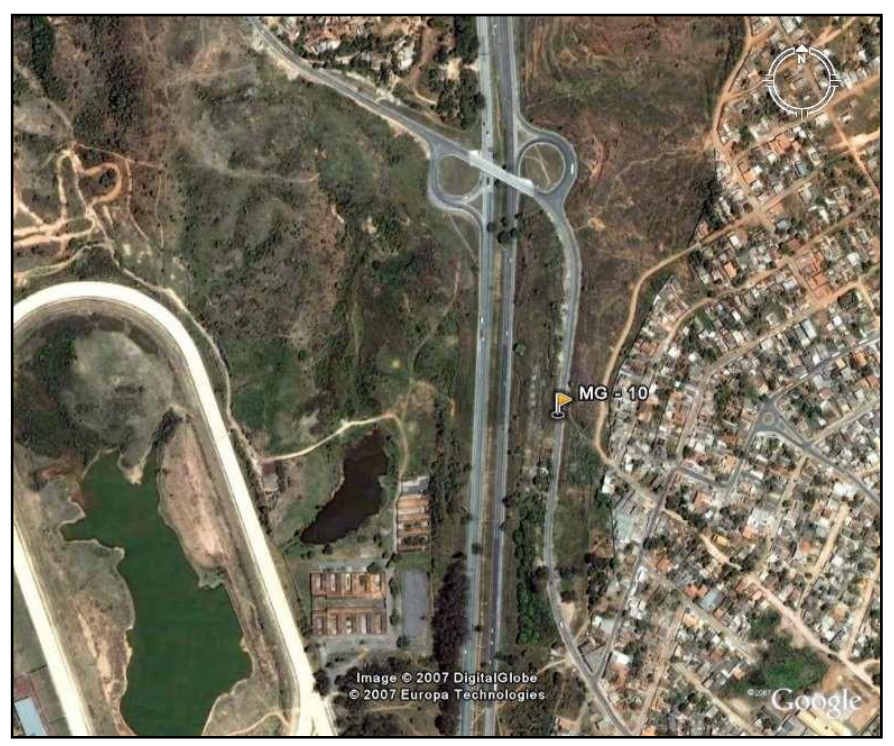

Fonte: Google Earth.

Nesse sentido, enquanto a geologia pode favorecer o aparecimento e crescimento de alguns itens (acessos, assentamentos de cidades, etc.), pode desfavorecer a instalação de certas edificações. A geologia deveria ser o primeiro item a ser estudado em qualquer construção civil em nosso país.

Na primeira parada foi observada a disposição espacial das siderúrgicas e indústrias cimenteiras, totalmente condicionadas à geologia local, assim como ocorre com as minas de minério de ferro na porção Centro-Sul do Quadrilátero Ferrífero.

Os municípios de Matozinhos e Prudente de Morais puderem ser avistados nesta primeira parada. Ambos, preservando passado histórico em suas edificações e acessos, tiveram seu desenvolvimento atrelado quase que fundamentalmente por estarem dentro do cinturão de desenvolvimento da Metropolitana. Caso contrário, teriam ou seriam de menor porte. Ou seja, aqui constata-se a existência e manutenção de município com base à influência de um maior núcleo urbano - RMBH. 
O trabalho de campo como metodologia de Ensino de Geografia: aplicabilidade no municipio de Sete Lagoas-MG

Ricardo Henrique Palhares; Alysson Cley de Souza Ferreira

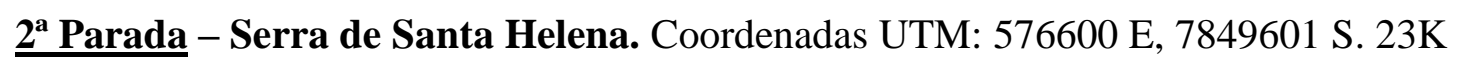

O dinamismo de Sete Lagoas pode ser observado na sua paisagem urbana. Contudo, a Serra de Santa Helena é um impedimento natural ao desenvolvimento físico de grande parte da cidade - a serra é uma das bordas da bacia do rio São Francisco (Figura 3). Com base em observações no mapa geológico local, pôde-se apontar as localizações de determinas formações geológicas e geomorfológicas, assim como correlacioná-las com a geografia urbana local.

Figura 3: Serra de Santa Helena

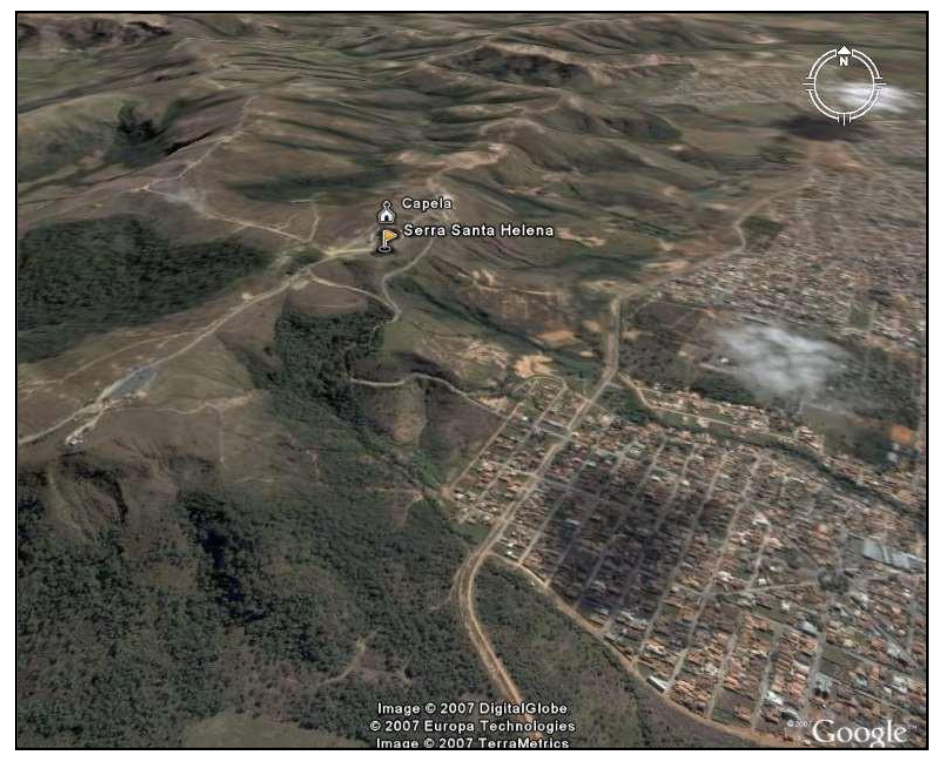

Fonte: Google Earth.

Nesta parada foi observado os aspectos inter-urbanos de Sete Lagoas (porte médio, autonomia municipal, riquezas minerais e naturais). A posição geográfica favoreceu dentro outros aspectos o de tornar Sete Lagoas uma cidade dormitório ou um lugar etapa, cujas pessoas migram para esta cidade e posteriormente para Belo Horizonte, com interações e dinamismos no contexto regional e interurbano.

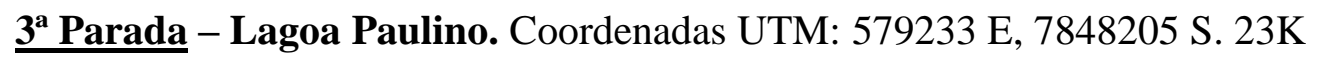

Nesta parada, o foco das análises foram as observações e considerações sobre a expansão do centro funcional (edificações, tipo, etc.) de Sete Lagoas; a formação de um centro principal funcional, e todos os demais subcentros. A localização do centro funcional 
O trabalho de campo como metodologia de Ensino de Geografia: aplicabilidade no municipio de Sete Lagoas-MG

Ricardo Henrique Palhares; Alysson Cley de Souza Ferreira

teve influência de aspectos físicos (geomorfologia), assim como sociais e do centro da cidade, que se tornou um subcentro.

Figura 4: Lagoa Paulino

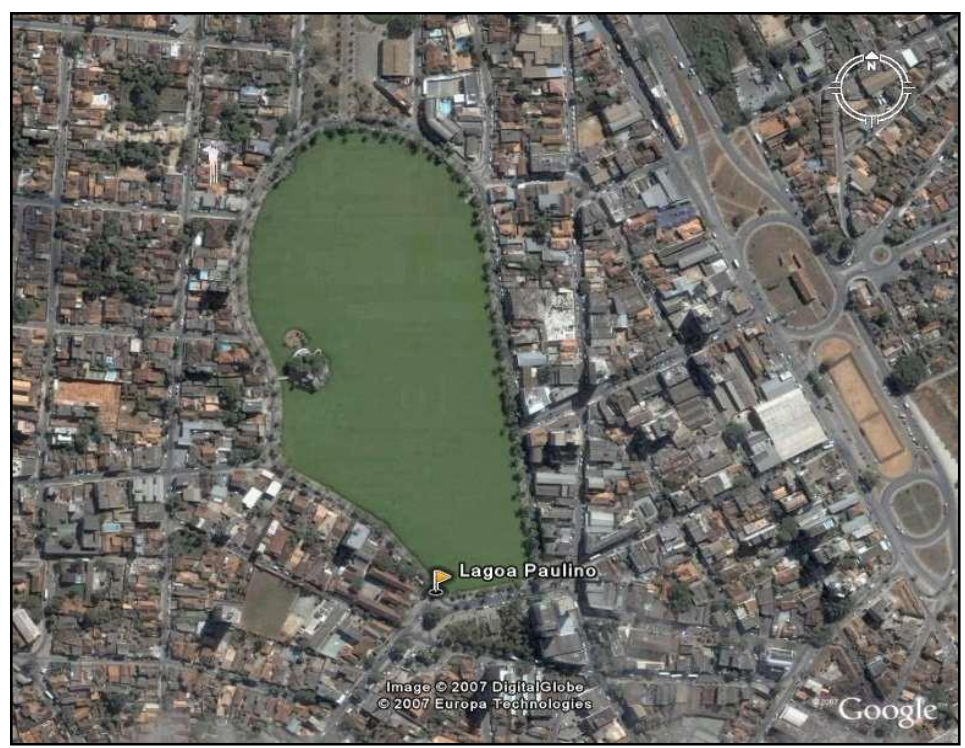

Fonte: Google Earth.

\section{Aspectos intra-urbanos de Sete Lagoas}

Ficou clara que a posição do centro funcional foi influenciada pela localização da lagoa (Figura 4). Assim como a localização dos subcentros foi influenciada pela posição do centro funcional. A cidade tornou-se perifericamente organizada, sendo que a geomorfologia favoreceu a extensão e distanciamento de bairros (mancha de óleo e núcleos separados), características de cidades médias.

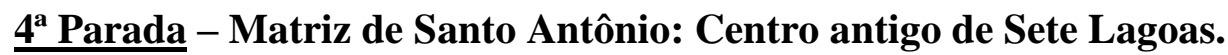

Coordenadas UTM: 579015 E, 7847388 S. 23K

Neste ponto foi possível observar e analisar o local onde se deu o início do povoamento, com suas ruas irregulares, típicas de cidades coloniais portuguesas. O centro principal que se localizava ali se mudou para outro local mais movimentado: pois o centro funcional não é fixo. O local da matriz, que antes era área central, agora tornou-se pericentral sendo que, futuramente pode ser subcentro ou perder importância. 
O trabalho de campo como metodologia de Ensino de Geografia: aplicabilidade no municipio de Sete Lagoas-MG

Ricardo Henrique Palhares; Alysson Cley de Souza Ferreira

Figura 5: Matriz de Santo Antônio

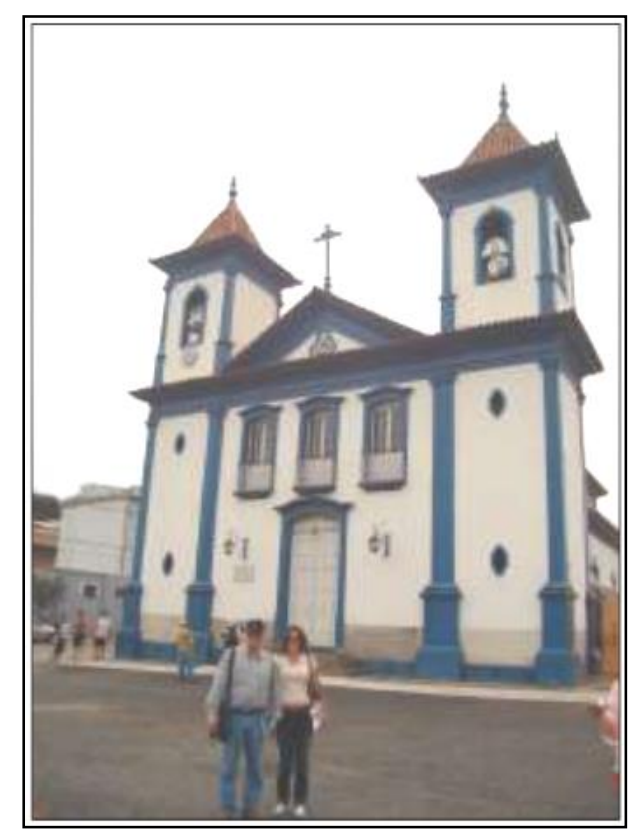

Fonte: do autor

Um espaço que exercia uma centralidade, com uma igreja (Figura 5), que mostrava um dos sinais de centralidade do passado, este espaço passa a ser um espaço pericentral com alguns equipamentos terciários presentes como o museu, algum comércio, mas sem uma concentração de equipamentos, predominando residências, que pode ser central do ponto de vista geográfico, locacional, mas não do ponto de vista funcional, que representa um espaço pericentral.

Percebemos que as funções não estão definidas para sempre, este centro que hoje é importante, pode no futuro, dependendo de novas centralidades pode virar um subcentro ou até mesmo perder esta função.

$\underline{\mathbf{5}^{\mathbf{a}} \text { Parada }}$ - Subcentro em bairro residencial. Coordenadas UTM: 579435 E, 7848365 S. $23 \mathrm{~K}$

Este subcentro é um prolongamento do centro funcional, já na zona pericentral: subcentro linear de extensa avenida (Figura 6). Ao longo da mesma, ocorrem outros subcentros cada vez menores. Toda a extensão, no passado, margeava linha férrea existente (Figura 7). Deste lineamento urbano central, existem vias arteriais perpendiculares, criadas devido à necessidade de capilaridade de acessos para as edificações que foram sendo construídas ao longo do tempo (outros subcentros). 
O trabalho de campo como metodologia de Ensino de Geografia: aplicabilidade no municipio de Sete Lagoas-MG

Ricardo Henrique Palhares; Alysson Cley de Souza Ferreira

Figura 6: Avenida Antônio Olinto

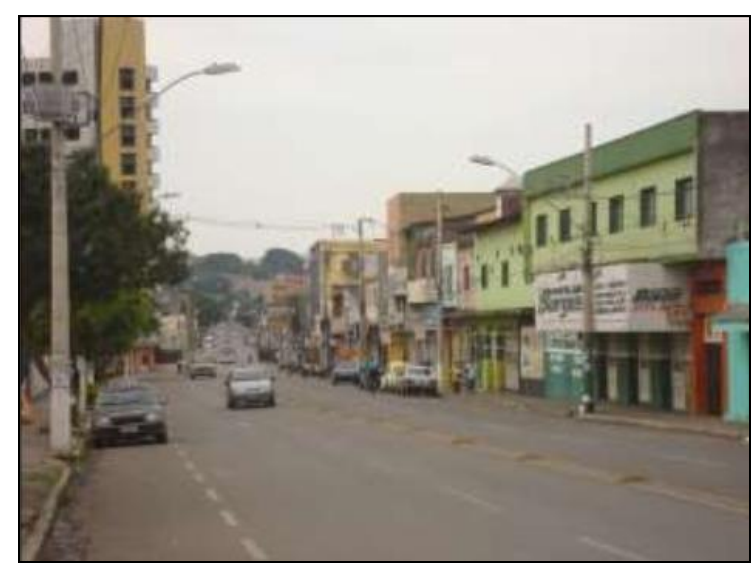

Fonte: do autor
Figura 7: Maria Fumaça - na antiga Estação de Sete Lagoas

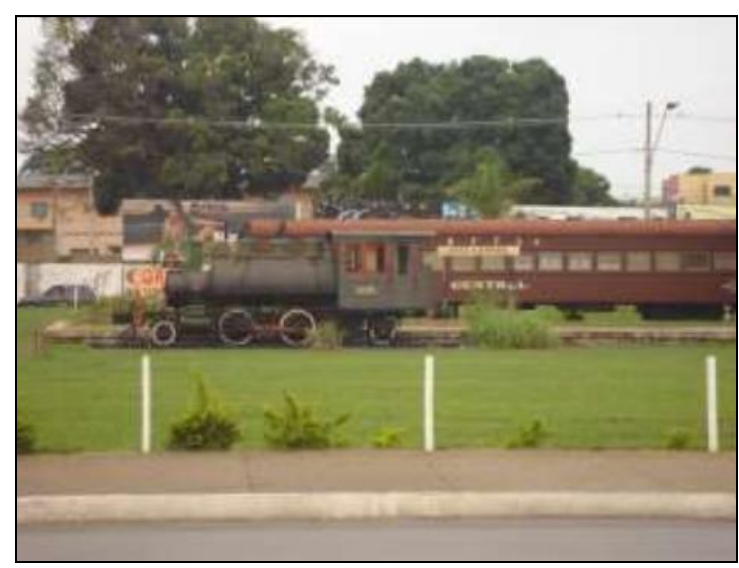

Fonte: do autor

Caminhando pelas vias arteriais deste subcentro linear, é evidente o indício típico de uma zona pericentral, com áreas residenciais de baixa densidade. Comparando este subcentro com o centro principal, é clara a diferença qualitativa e funcional entre ambos, apresentando uma descontinuidade do espaço de serviços para o residencial.

É importante analisar estas unidades, centralidades funcionais que dão vida para cada zona, região. Foram analisados centros e subcentros terciários, observando no final do trabalho de campo um subcentro industrial, com possui características diferenciadas, ocupando um espaço muito maior, gerando recursos às vezes muito maiores, sendo também uma fonte de emprego considerável, apesar de estar comprovado que o setor que gera mais empregos hoje é o setor terciário.

\section{CONSIDERAÇÕES FINAIS}

Tendo em vista o propósito deste artigo, os resultados de campo e sua contribuição para o ensino aprendizagem de Geografia, podemos dividir os resultados em dois tipos: gerais e específicos. Como resultado geral, a consideração sobre a necessidade de se ter bem planejado (teoria e prática) para toda e qualquer atividade de campo que se possa fazer, seja de cunho acadêmico ou profissional. E nesta preparação, a presença de pessoas especializadas ou conhecedoras do que se vai observar e analisar é de fundamental importância.

A segunda etapa, mais específica, evidenciou as observações e análises do trabalho de campo realizado em Sete Lagoas. Esta etapa só foi possível ser compilada após terem 
O trabalho de campo como metodologia de Ensino de Geografia: aplicabilidade no municipio de Sete Lagoas-MG

Ricardo Henrique Palhares; Alysson Cley de Souza Ferreira

sido aditados e executados todos os itens ou programação definida para a referida atividade de campo.

Em suma, a prática de campo proporciona a formação do profissional de Geografia, e áreas afins, a capacidade de integrar a teoria vista em sala de aula com a realidade da prática de campo, aprofundando o conhecimento acerca da temática proposta para a elaboração desse artigo.

Acreditamos que este tipo de metodologia visou não só contribuir, mas também resgatar os estudos sobre a cidade de Sete Lagoas e sua região, seus processos e interações. Esperamos que os resultados demonstrados venham elucidar questões referentes à temática da Geografia Urbana e colaborar cada vez mais para estudos futuros no ensino de Geografia.

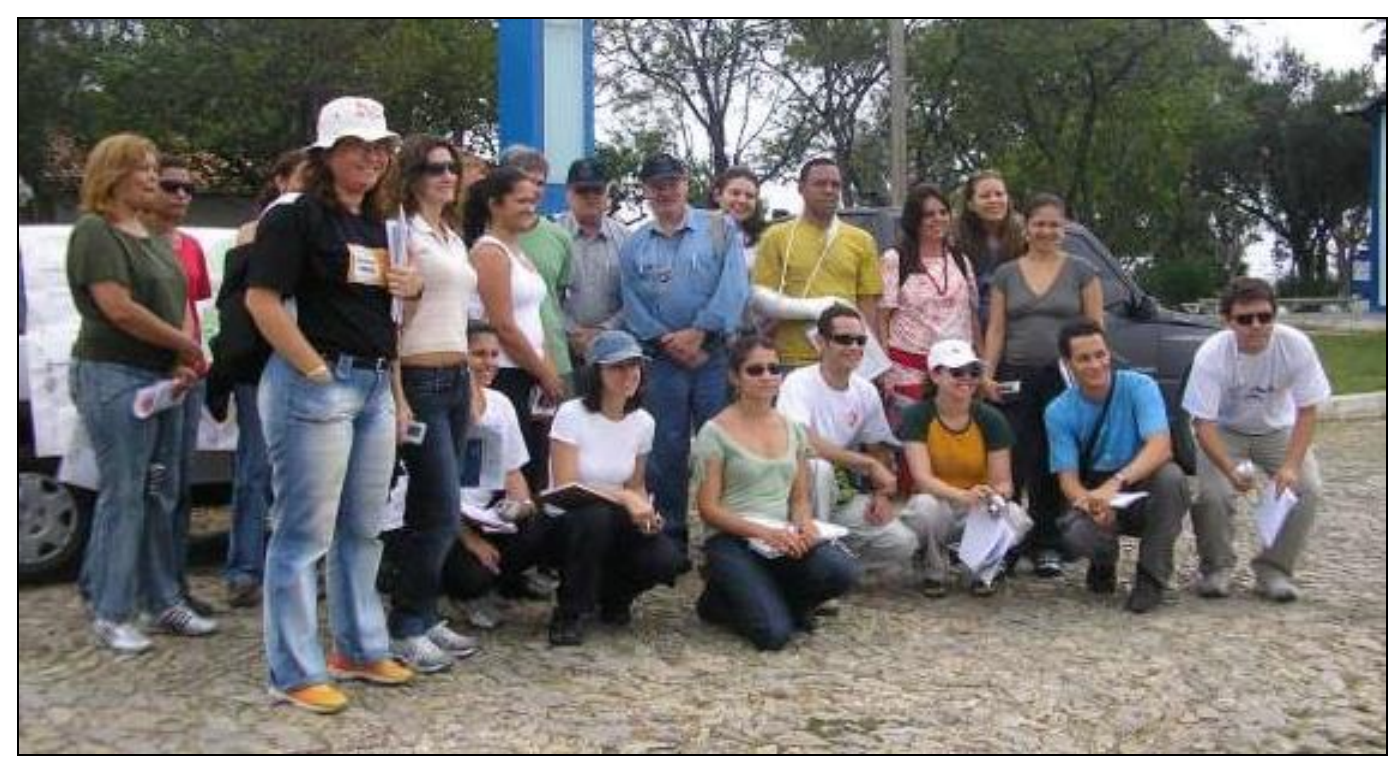

Equipe do trabalho de campo em Sete Lagoas. No centro, da esquerda para direita, os professores José Irineu Rigotti, Oswaldo Bueno Amorim Filho e Heinz Charles Kohler, tendo ao redor seus alunos do Programa de Pós-Graduação em Geografia Tratamento da Informação Espacial - PUC Minas. Data: nov. 2007. 
O trabalho de campo como metodologia de Ensino de Geografia: aplicabilidade no municipio de Sete Lagoas-MG

Ricardo Henrique Palhares; Alysson Cley de Souza Ferreira

\section{Referências}

ALENTEJANO, P. R. R.; ROCHA-LEÃO, O. M. Trabalho de Campo: uma ferramenta essencial para os geógrafos ou um instrumento banalizado? Boletim Paulista de Geografia, São Paulo, nº 84, p. 51-57. 2006.

AMORIM FILHO, O. B.; SENA FILHO, N. A morfologia das cidades médias. Goiânia: Ed. Vieira, 2005.

CAVALCANTI, L. de S. Geografia, escola e construção de conhecimentos. Campinas: Papirus, 1998.

INSTITUTO BRASILEIRO DE GEOGRAFIA E ESTATÍSTICA - IBGE. Cidades e Estado. Estimativas da população, 2019. 